\title{
Л.Б. Скавка*
}

\author{
СОЦИАЛЬНЫЙ СТАТУС КИНО \\ КАК ФЕНОМЕНА ХУДОЖЕСТВЕННОЙ КУЛЬТУРЫ
}

\begin{abstract}
В настоящей статье автор проводит обзор философских представлений о кино как о самостоятельном виде искусства и художественной культуры. В статье рассмотрен спектр восприятия феномена кино от развлекательной технической новинки до авангардного и академического искусства.
\end{abstract}

Ключевые слова: философия кино, функции кино, теория кино, художественная культура

The social status of cinema as an artistic phenomenon. LARISA B. SKAVKA (Far Eastern Federal University)

The author presents an overview of the philosophical concepts that treat cinema as an independent artistic phenomenon, paying special attention to the ideas of J. Deleuze and J. Ortega y Gasset. The article shows that the spectrum of its perception varies from seeing it as an entertaining technical novelty to considering it as avant-garde and academic art.

Keywords: philosophy of cinema, functions of cinema, theory of cinema, artistic phenomenon

На примере кинематографа как нельзя лучше можно наблюдать, каким образом развитие техники влияет на способы создания и функционирования духовной культуры. В ХХ в. техника перестала быть просто способом упростить и облегчить человеческий труд, она превратилась в «живой, неиссякаемый источник человеческой деятельности» [16, с. 220], в том числе и художественной. В настоящее время кинематограф представляет собой один из наиболее актуальных и интенсивно развивающихся видов искусства. Можно с полной уверенностью сказать, что кино как феномен художественной культуры оказывает существенное воздействие на современную социальную действительность.

Современное кино представлено в крайне разнообразных формах: документальное и игровое, коммерческое и альтернативное, профессиональное и любительское. Что касается эстетической, художественной ценности большого числа кинопродуктов, то на этот счет в киноведческой среде существуют совершенно разные мнения. Стоит отметить, что существенная часть кинофильмов, например, учебные и научно-популярные фильмы, не имеют отношения к художественной культуре, кроме того, на вопрос о причастности к искусству некоторых документальных и даже художественных фильмов не всегда может быть получен однозначный и окончательный ответ.

Кинематограф, как и большая часть видов художественного творчества, первоначально выполнял в обществе бытовые, утилитарные функции - развлекательную, а позднее - инфор-

* СКАВКА Лариса Богдановна, кандидат философских наук, доцент Департамента философии и религиоведения Школы искусств и гуманитарных наук Дальневосточного федерального университета.

E-mail: skavka.lb@dvfu.ru

(C) Скавка Л.Б., 2021 
мационную. И лишь спустя некоторое время, после периода горячих дискуссий в искусствоведческой среде, кино обрело статус искусства. Так кинематограф, формируя свой собственный изобразительный язык, сложную систему монтажа, обогащаясь специфическими выразительными средствами киноактеров, операторскими находками, прошел путь от технического средства репродуцирования до нового способа художественного видения действительности. «Искусство кино предстало перед миром как новая, десятая муза» [20, с. 17]. Кино стало и частью официальной художественной культуры, и академической дисциплиной: в 1960-е - 1970-е гг. в ведущих университетах мира возникли факультеты, где изучали основы кинотворчества и теорию кино [17, с. 212].

Кино обязано своим появлением достижениям науки и техники, но при этом оно представляет собой результат многовекового развития искусства. Кинематограф не раз сравнивали с живописью, которая с его возникновением обрела движение, с литературой, которая благодаря ему стала зримой, а также с театром, перенесенным на пленку. «...Фильм пользуется элементами литературы - сюжетом, драматургией, словесным текстом, метафорой и так далее; театра - актерской игрой, гримом, декорацией, освещением; изобразительных искусств - композицией мизанкадра, построением перспективы, трактовкой колорита и цветовой гаммы; музыки, непосредственно звучащей с экрана или опосредованной в кинематографическом ритме...» $[12$, с. 6]. Соединение перечисленных компонентов сделало кинематограф уникальным видом художественного творчества, в рамках которого произошла своеобразная переработка опыта, полученного в результате эстетической эволюции традиционного искусства.

Современный французский философ Ален Бадью называет кинематограф «нечистым» [21, p. 226] искусством, имея в виду смешанный, сложный характер кинотворчества и наличие множества материальных условий для реализации любого кинематографического замысла. Если поэт и художник для создания своих произведений могут обойтись двумя-тремя вещественными принадлежностями (например, ручка и лист или краски и холст), то режиссер нуждается в целом комплексе разнообразных материалов - это и техническое оснащение, и место для съемок, и сценарий, и актеры, и съемочная группа, и, конечно же, немало финансо- вых ресурсов, и многое другое. Таким образом, для того, чтобы заниматься творчеством в области кино, далеко недостаточно иметь талант и знания, этим кинематограф существенно отличается от других видов искусства.

Интересна точка зрения А. Моля, который утверждал, что кинематограф является не уникальным и самодостаточным видом художественной культуры, а лишь преемником театра, который вынужден был видоизменяться в соответствии с условиями современности [14, c. 262]. Новый этап социодинамики культуры повлек за собой определенные требования к способам демонстрации произведений искусства: максимальный охват социального поля, высокий уровень доступности художественных сообщений для членов общества. Таким образом, кино стало синтезом более древнего театрального искусства и современных технических возможностей с целью удовлетворения потребностей социума.

Итак, сочетание и особая адаптация в кинематографе признаков других явлений художественного творчества привели к восприятию кино как синтетического искусства. Большинство терминов киноведения являются классическими терминами эстетики и искусствознания, которые использовались задолго до появления кино. Что касается, казалось бы, сугубо киноведческих терминов, то С.М. Эйзенштейн в своих работах настаивал на их докинематографическом происхождении. Известный русский режиссер и теоретик кино утверждал, что такие приемы, как монтаж, план, ракурс широко применялись в литературе, театре, живописи и других видах искусства [19, с. 14-15].

Несмотря на то, что кинематограф, как мы показали выше, можно назвать продуктом синтеза разных искусств, он изначально представлял собой уникальный феномен художественной культуры, создающий посредством экрана новую, невиданную прежде и неповторимую, живую, целостную и плотную реальность.

Пройдя стадию становления и прочно заняв свою нишу в современной культуре, кинематограф стал оказывать существенное влияние на развитие других сфер духовной жизни общества. Г.М. Маклюэн, например, утверждает, что один из литературных приемов, известный как «поток сознания», заимствован писателями именно из кино $[11$, с. 336]. Этот способ изложения дает возможность читателю максимально отождествить себя с тем или иным ху- 
дожественным персонажем, при этом эффект, оказываемый на читателя книги, приближается к эффекту, который испытывает зритель во время просмотра кинофильма.

По мнению канадского мыслителя, вообще значительная часть литературы модернизма развивалась под влиянием кинематографа, телевидения и других современных средств коммуникации. Г.М. Маклюэн считает, что обращение к инновационному творчеству таких писателей, как Э. Паунд, Т.С. Элиот, Д. Джойс может способствовать более ясному пониманию феноменов нынешней системы коммуникации и их роли в обществе [3, с. 27]. Например, в художественных произведениях Д. Джойса затронуты вопросы сосуществования вербальной и визуальной культур, а также отражены актуальные проблемы противостояния кино, телевидения и радио друг другу и печатным источникам информации [3, с. 24, 26].

Философия, как дисциплина, наиболее чутко реагирующая на любые существенные изменения в культуре и обществе, также не избежала влияния кинематографа. Так, феномен кино используется французским философом А. Бергсоном в качестве наиболее адекватной иллюстрации устройства человеческого мышления: «Механизм нашего обычного познания имеет кинематографический характер» [4, с. 339]. Кинематографическая лента, с помощью которой связываются воедино множество неподвижных кадров, создает имитацию движения. Подобным же образом человеческий интеллект, анализируя индивидуальные движения вещей в реальности, продуцирует некое абстрактное, искусственное представление о движении вообще. «Восприятие, образование понятий, язык создаются в общем именно таким образом. Когда дело идет о том, чтобы мыслить процессы становления или выражать их в словах, или хотя бы воспринимать их, мы просто заставляем действовать известного рода внутренний кинематограф» [4, с. 339].

Согласно А. Бергсону, такой кинематографический метод познания вещей отвечает интересам науки, имеет определенную практическую ценность, вносит ясность в деятельность человека. Но вместе с тем описанный способ мышления заводит познание в тупик, способствуя формированию ошибочного, механического, отрывочного мировоззрения, потому что внутренняя сущность таких явлений, как время, движение, развитие, остается для человека непознанной. Французский философ убежден: для того, чтобы начать изучение объективных феноменов, а не их кинематографических подражаний, необходимо «отказаться от кинематографических привычек нашего интеллекта» [4, c. 347].

По мнению другого французского философа - М. Мерло-Понти, кинематограф, как молодой вид искусства, по своей сути как нельзя лучше соответствует идеям новой психологии и современной философии, он приспособлен к обнаружению глубинной связи между внутренним и внешним, между субъектом и миром (например, в кино внутренние состояния человека переданы через внешние проявления, через его поведение, мимику, жесты, через взаимодействие с вещами и другими людьми) [13].

Еще один французский философ - Ж. Делёз - осуществил, пожалуй, самое масштабное философское исследование феномена кино. В отличие от А. Бергсона, Ж. Делёз в своих работах «Кино-1. Образ-движение» и «Кино-2. Образ-время» рассматривает кинематограф не как совокупность отдельных кадров, имитирующую движение, а как живой эволюционирующий организм. Опираясь на концепции таких разноплановых философов, как А. Бергсон, Ф. Ницше и Ч. Пирс, Ж. Делёз создал смелую и оригинальную теорию кино, не укладывающуюся в рамки существовавших ранее искусствоведческих и семиологических представлений о кинематографе. Вышеупомянутые работы французского философа представляют собой нечто большее, чем анализ истории развития кино, его школ и направлений, или теоретическое исследование киноискусства. Кино в данном случае выступает феноменом, постижение которого напрямую связано с важнейшими философскими проблемами, такими как проблемы движения, времени, коммуникации, восприятия, языка.

По мнению Ж. Делёза, именно философы должны заниматься созданием теории кино, изучать концепты, порожденные кинематографом и являющиеся не менее действительными, чем кинематограф. «Само кино представляет собой новую практику образов и знаков, а философия должна создать теорию последней как концептуальную практику» [7, с. 615].

Необходимо обратить внимание на то, что большинство философов XX в., даже те, кто занимался исследованием визуальных образов, не воспринимали кино всерьез, то есть не рас- 
сматривали его в качестве объекта философского анализа. Например, по мнению М. Мерло-Понти, которого больше интересовало изучение живописи, кинематограф не является истинным союзником для философии, а Р. Барт утверждает, что фотоискусство гораздо более философично, нежели кино [2, с. 16]. Ж. Делёз, наоборот, видит в изучении кинематографического материала возможности для нового витка развития философии. Кинематограф, будучи «стихией движения и изменчивости» [2, с. 13], изображает мир в его становлении. Согласно французскому философу, феноменологический метод не состоятелен в случае с постижением сущности кино, ведь кинематограф формирует совершенно новый вид движения, не укладывающийся в представления феноменологов о движении и создающий новый способ восприятия действительности.

Вот что говорит российский философ и искусствовед О. Аронсон о делёзовском понимании кинематографа: «Кино открывает нам возвращение мысли, забытой в эпоху господства субъекта. У Делёза оно оказывается “ближе” к мысли, чем фотография и литература, почти совпадая с тем, как устроена сама мысль. Развитие же кинематографа ... идет по пути все большей виртуализации (наращивание световых, цветовых, звуковых и прочих эффектов), то есть по тому пути, где реальность мысли оказывается более ощутимой, чем та физическая реальность, которую кино якобы “повторяет”» [2, с. 19].

Ж. Делёз считал уместным и даже необходимым сравнение гениальных кинорежиссеров не только с представителями живописи, музыки и других видов искусства, но и с великими мыслителями, философами. Отличие первых в том, что они оперируют в своей работе не понятиями, а образами [6, с. 39]. Именно изучению сущности и классификации кинематографических образов французский философ посвятил свои труды о кино.

Для анализа кино Ж. Делёз применяет заимствованные у А. Бергсона понятия «образ-движение» и «образ-время», открытие которых Ж. Делёз считает великим достижением, имеющим огромное значение в философии [6, с. 39]. Стоит отметить, что сам А. Бергсон никогда не использовал указанные понятия по отношению к кино и вообще довольно критично относился к кинематографу.

В концепции французского философа вышеупомянутые образ-движение и образ-время, являясь, по сути, инструментами мышления кинематографистов, выступают фундаментом теории кино [9, с. 134]. Ж. Делёз считает, что кинематограф обрел свою истинную сущность не сразу, а лишь тогда, когда метод неподвижной, фиксированной съемки остался в прошлом. Образы-движения появились благодаря монтажу, независимости кинокамеры от проекционного аппарата и возможности создавать подвижные планы [1, с. 42]. Образы-движения, не содержащие какую-либо конкретную информацию об изображаемом объекте, а свободно переходящие из одной системы истолкования в другую, и составляют материю кино. Дальнейшая эволюция кинематографа, связанная с появлением звука и цвета, развитием других технических средств кино привела к возникновению следующего типа образа - образа-времени, так «современное кино порвало с повествовательностью» [5, с. 140]. Образ-время является еще более сложным элементом кино, знаком, воплощающим уже не столько движение, мерой которого является время, сколько время, в перспективу которого превращается движение. Если образы-движения складываются в хронологически и повествовательно упорядоченную историю, то образы-времени открывают в пространстве кинофильма множество временных и смысловых, иррационально связанных между собой пластов, делают возможным сосуществование настоящего, прошлого и будущего, реального и воображаемого, сознательного и бессознательного.

В своей двухтомной работе о кино Ж. Делёз приводит также более подробную классификацию кинематографических образов: образ-свет, образ-перцепция, образ-действие, образ-эмоция, образ-переживание, образ-импульс и др. Французский философ утверждает, что каждый кинообраз может содержать в себе огромное количество измерений.

Образная система кино создает виртуальную реальность, которая не копирует действительность и не противопоставлена ей, а является полноценной частью последней. Именно работа над виртуализацией реальности является тем, что, согласно Ж. Делёзу, сближает кино и философию. Однако благодаря стремительному развитию кинематографа процесс виртуализации реальности достиг огромного масштаба. Философия, в свою очередь, должна теперь пересмотреть свою роль в освоении этого нового образного пространства, выйти за свои преж- 
ние границы, особенно в свете пессимистических настроений по поводу статуса философии в системе современного знания. И прежде всего философия должна иметь дело с новым субъектом, который обладает иным, отличным от прежнего, опытом восприятия и максимально открыт воздействию кинообразов. Делёзовская концепция такого субъекта, сформированного киноискусством, по мнению О. Аронсона, имеет много общего с идеями В. Беньямина и 3. Кракауэра, утверждавшими, что кинозритель представляет собой уже не субъекта в его классическом, картезианском понимании, а деиндивидуализированную, депсихологизированную массу [2, с. 14-15].

Ж. Делёз рассматривает кино как полноценную часть истории искусств. Крупные мастера кино находят новые, уникальные и самостоятельные формы самовыражения. Однако французский философ называет кинематограф индустриальным искусством, тесно связанным с экономикой и производством. В связи с этим в сфере кино производится больше некачественной продукции, чем в других сферах искусства, а талантливые авторы более уязвимы, чем представители других видов творческой деятельности [6, с. 39].

Кино, вобрав в себя наследие предшествующих видов искусства, превосходит последние в силе своих образов, обладающих самодвижением. Кинематограф «использует образы другого рода в собственном режиме, наделяет мощью то, что было лишь возможностью» [7, c. 468]. Образ-движение обладает большим воздействием на публику, в связи с этим многие из тех, кто стоял у истоков практики и теории кино (в том числе Д. Вертов и С. Эйзенштейн), надеялись, что кинематограф, вызывающий в определенном смысле слова шок у зрителя, заставит массы мыслить, что, в свою очередь, приведет к преобразованию социальной реальности.

Ж. Делёз критически относится к подобной вере в волшебную силу кино как массового искусства. Во-первых, потому что, по его мнению, ни один вид художественного творчества не способен превратить обычных людей в мыслителей. А во-вторых, потому что среди кинематографической продукции всегда будет много некачественных, экспериментальных, а также коммерчески или пропагандистки ориентированных фильмов. Однако французский философ считает несомненным то, что кино оказывает шоковое воздействие на аудиторию, а также то, что мысль и образ в кинематографе неразрывно связаны между собой и взаимно переходят друг в друга во время производства и просмотра. В кинематографическом круге, состоящем из режиссера, фильма и зрителя, происходит движение от эмоционального шокового впечатления, вызванного образами, до сознательной мысли, а затем от мысли - опять к чувственно воспринимаемым образам.

Анализ статуса и роли кинематографа в современном обществе предполагает обращение к концепциям, раскрывающим социальные функции искусства в целом. В частности, для более глубокого понимания феномена кино, стоит рассмотреть идеи испанского философа и социолога Х. Ортеги-и-Гассета, который посвятил одну из своих работ изучению искусства с социологической точки зрения.

Испанский философ утверждал, что по эффекту, который производят те или иные явления искусства в обществе, можно судить о структуре и состоянии самого общества. Чистое, далекое от утилитарности и повседневности искусство, способное доставить подлинное эстетическое наслаждение, обычно воспринимается большинством членов общества негативно, враждебно. И дело здесь не в различиях эстетических вкусов и предпочтений, не в том, что представителям массы не нравится произведение искусства, а в том, что они не понимают, не способны его понять: «...Новое искусство обращается к особо одаренному меньшинству. Отсюда - раздражение в массе. Когда кому-то не нравится произведение искусства именно поскольку оно понятно, этот человек чувствует свое превосходство над ним, и тогда раздражению нет места. Но когда вещь не нравится потому, что не все понятно, человек ощущает себя униженным, начинает смутно подозревать свою несостоятельность, неполноценность, которую стремится компенсировать возмущенным, яростным самоутверждением перед лицом произведения» [15, с. 221].

Что касается современного киноискусства, то его продукты в большинстве своем ориентированы на потребности масс, восприятие же интеллектуального, авангардного кино предполагает наличие у аудитории особых знаний и навыков. Таким образом, сегодня зачастую не зритель судит кинопроизведение, а оно - своего зрителя [1, с. 10].

Итак, искусство, в том числе и кино, способно выявлять в структуре общества два класса 
людей, различающихся в способности воспринимать художественное творчество. Подобное разделение социума на заурядных и выдающихся его членов существовало всегда, и это, по мнению Х. Ортеги-и-Гассета, данность, которую необходимо принять. Испанский философ настаивал на том, что преодоление современного заблуждения о всестороннем равенстве людей - это важный шаг на пути к решению многих социальных проблем.

Если следовать концепции испанского философа, в рамках которой он различает нежизнеподобное, высокое, элитарное и реалистическое, демократическое искусство, то кино, отображающее действительность и ориентированное на массового зрителя, следовало бы отнести ко второму виду художественного творчества. Например, французский кинорежиссер и теоретик кино Луи Деллюк отмечает, что восприятие произведений кинематографа не требует «умственной подготовки» [8, с. 152], в отличие от произведений литературы или музыки. Особенность киноискусства заключается в его предназначенности толпе. Л. Деллюка удивляет тот факт, что представители простого народа, некультурные и необразованные, невосприимчивые к другим видам художественного творчества, проявляют способность чувствовать и понимать искусство, восхищаться им, если речь идет о кино.

Между тем, определение социальной роли кинематографа осложняется тем обстоятельством, что он не является однородным, цельным феноменом, ведь в среде киноведов принято разграничивать коммерческое, массовое и авангардное, интеллектуальное кино.

Первоначально кинематограф представлял собой сугубо развлекательное зрелище, предназначенное для извлечения прибыли. Тем не менее, «родившись среди презираемых “низких" жанров, оно (кино. - прим. авт.) довольно быстро проникло в сферу “благородных” искусств: классического театра, серьезной, исторической литературы и т.д.» [18, с. 88]. О высоком уровне культурной ценности кинофильмов можно судить по тому факту, что фразы, жесты и другие детали из произведений кинематографа зачастую становятся объектами цитирования, наряду с высказываниями из произведений литературы.

Уже в самом начале XX в. существовало разделение кинотеатров на центральные, фешенебельные, предназначенные для элитарной, интеллигентной публики и окраинные, более простые, для широких масс. Интересным представляется то, что репертуары этих кинотеатров были совершенно разными - жанры и сюжеты кинокартин подбирались под вкусы определенного класса зрительской аудитории [10, с. 45-46].

Стоит упомянуть, что процессы возрастания популярности и массовости кино и процессы повышения статуса кино до уровня искусства проходили параллельно друг другу. Коммерческое кинопроизводство набирало обороты, формировались полюбившиеся публике жанры, в рамках которых действовали определенные устойчивые каноны или шаблоны создания фильмов как продуктов массового потребления. Другое кино, менее распространенное, занявшее нишу истинно благородного и серьезного искусства, близкого живописи, музыке, литературе по предъявляемым к ним высоким требованиям, стало средством непрерывного художественного поиска, разноаспектного познания действительности, свободного творческого самовыражения. Целевой аудиторией такого кинематографа был и остается достаточно узкий круг людей. Представители киноавангарда никогда не ставили перед собой задачу сделать свои картины ценными и популярными для массового зрителя [22, р. 17].

Противопоставление коммерческого и авторского кино, несмотря ни на что, весьма условно. Существует достаточно большое количество кинофильмов, сочетающих в себе, с одной стороны, подлинные художественные достоинства и, с другой, массовую популярность и прибыльность. Здесь также стоит отметить, что иногда режиссеры, создающие в начале своего творческого пути экспериментальные, авангардные картины, позже работают в сфере коммерческого кино, ориентируясь на массовую аудиторию.

\section{СПИСОК ЛИТЕРАТУРЫ}

1. Абдуллаева 3. Кира Муратова: Искусство кино. М.: Новое литературное обозрение, 2008.

2. Аронсон О. Язык времени // Делёз Ж. Кино. М.: Ad Marginem, 2004. С. 11-36.

3. Архангельская И.Б. Герберт Маршалл Маклюэн: от исследования литературы к теории медиа: автореф. дисс. ... д. филол. н. М., 2009.

4. Бергсон А. Творческая эволюция // Бергсон А. Творческая эволюция. Материя и память. Минск: Харвест, 1999. С. 8-412.

5. Делёз Ж. Интервью по поводу книги «Кадр-движение» // Z. Философско-культурологический журнал. 2000. № 1-2. С. 136-144. 
6. Делёз Ж. Кино 1. Образ-движение // Делёз Ж. Кино. М.: Ad Marginem, 2004. С. 37-288.

7. Делёз Ж. Кино 2. Образ-время // Делёз Ж. Кино. М.: Ad Marginem, 2004. С. 289-615.

8. Деллюк Л. Фотогения. М.: Новые вехи, 1924.

9. Кошовец О. Кино-Фило-София Ж. Делеза // Z. Философско-культурологический журнал. 2000. № 1-2. С. 134-135.

10. Кувшинова М.Ю. Кино как визуальный код. СПб.: Мастерская «Сеанс», 2014.

11. Маклюэн Г.М. Понимание медиа. М.: Кучково поле, 2011.

12. Мейлах М. Пластика фильма. СПб.: РИИИ, 2006.

13. Мерло-Понти М. Кино и новая психология // Киноведческие записки. 1992. № 16. C. 13-22.

14. Моль А. Социодинамика культуры. М.: Прогресс, 1973.

15. Ортега-и-Гассет X. Дегуманизация искусства // Ортега-и-Гассет Х. Эстетика. Философия культуры. М.: Искусство, 1991. С. 218260.

16. Ортега-и-Гассет Х. Размышления о технике // Ортега-и-Гассет Х. Избранные труды. М.: Весь Мир, 2000. С. 164-232.

17. Разлогов К.Э. Искусство экрана: от синематографа до Интернета. М.: РОССПЭН, 2010.

18. Разлогов К.Э. Конвейер грез и психологическая война. Кино и общественно-политическая борьба на Западе. 70-80-е годы. М.: Политиздат, 1986.

19. Соколов В.С. Киноведение как наука. М.: Канон+; РООИ Реабилитация, 2010.

20. Фрейлих С.И. Теория кино: от Эйзенштейна до Тарковского. М.: Академический проект, 2002.

21. Badiou, A., 2013. Cinema. Cambridge: Polity Press.

22. Goldmann, A., 1970. Cinéma et société moderne. Paris: Anthropos.

\section{REFERENCES}

1. Abdullaeva, Z., 2008. Kira Muratova: Iskusstvo kino [Kira Muratova: The art of cinema]. Moskva: Novoe literaturnoe obozrenie. (in Russ)

2. Aronson, O., 2004. Yazyk vremeni [The language of time]. In: Deleuze, J., 2004. Kino. Moskva: Ad Marginem, pp. 11-36. (in Russ)

3. Arkhangel'skaya, I.B., 2009. Gerbert Marshall Maklyuen: ot issledovaniya literatury k teorii media [Herbert Marshall McLuhen: from literature studies towards the theory of media], avtoreferat dissertatsii doktora filologicheskikh nauk. Moskva. (in Russ)

4. Bergson, H., 1999. Tvorcheskaya evolyutsiya [Creative evolution]. In: Bergson, H., 1999. Tvorcheskaya evolyutsiya. Materiya i pamyat'. Minsk: Kharvest, pp. 8-412. (in Russ)

5. Deleuze, J., 2000. Interv'yu po povodu knigi «Kadr-dvizhenie» [Interview about the book «The Movement-image»], Z. Filosofskokul'turologicheskii zhurnal, no. 1-2, pp. 136-144. (in Russ)

6. Deleuze, J., 2004. Kino 1. Obraz-dvizhenie [Cinema 1: The Movement-image]. In: Deleuze, J., 2004. Kino. Moskva: Ad Marginem, pp. 37-288. (in Russ)

7. Deleuze, J., 2004. Kino 2. Obraz-vremya [Cinema 2: The Time-image]. In: Deleuze, J., 2004. Kino. Moskva: Ad Marginem, pp. 289-615. (in Russ)

8. Dellyuk,L., 1924. Fotogeniya [Photogenicity]. Moskva: Novye vekhi. (in Russ)

9. Koshovec, O., 2000. Kino-Filo-Sofiya Zh. Delyoza [The cinema-philsophy of J. Deleuze], Filosofsko-kul'turologicheskii zhurnal, no. 1-2, pp. 134-135. (in Russ)

10. Kuvshinova, M.Yu., 2014. Kino kak vizual'nyi kod [Cinema as a visual code]. SanktPeterburg: Masterskaya «Seans». (in Russ)

11. McLuhan, H.M., 2011. Ponimanie media [Understanding media]. Moskva: Kuchkovo pole. (in Russ)

12. Meilakh, M., 2006. Plastika fil'ma [The plastique of cinema]. Sankt-Peterburg: RIII. (in Russ)

13. Merleau-Ponty, M., 1992. Kino i novaya psikhologiya [Cinema and the new psychology], Kinovedcheskie zapiski, no. 16, pp. 13-22. (in Russ)

14. Mol', A., 1973. Sotsiodinamika kul'tury [Sociodynamics of culture]. Moskva: Progress. (in Russ)

15. Ortega y Gasset, J., 1991. Degumanizatsiya iskusstva [The dehumanization of art]. In: Ortega y Gasset, J., 1991. Estetika. Filosofiya kul'tury. Moskva: Iskusstvo, pp. 218-260. (in Russ)

16. Ortega y Gasset, J., 2000. Razmyshleniya o tekhnike [Meditation on the technique]. In: Ortega y Gasset, J., 2000. Izbrannye trudy. Moskva: Ves' Mir, pp. 164-232. (in Russ)

17. Razlogov, K.E., 2010. Iskusstvo ekrana: ot sinematografa do Interneta [The art of the screen: from cinematography to Internet]. Moskva: ROSSPEN. (in Russ) 
18. Razlogov, K.E., 1986. Konveier grez i psikhologicheskaya voina. Kino i obshchestvennopoliticheskaya bor'ba na Zapade. 70-80-e gody [The conveyor of dreams and psychological warfare. Cinema and socio-political activism in the West. 1970s and 1980s]. Moskva: Politizdat. (in Russ)

19. Sokolov, V.S., 2010. Kinovedenie kak nauka [Cinema studies as a discipline]. Moskva: Kanon+; ROOI Reabilitatsiya. (in Russ)
20. Freilikh, S.I., 2002. Teoriya kino: ot Eizenshteina do Tarkovskogo [The theory of the cinema: from Eisenstein to Tarkovsky]. Moskva: Akademicheskii proekt. (in Russ.)

21. Badiou, A., 2013. Cinema. Cambridge: Polity Press.

22. Goldmann, A., 1970. Cinéma et société moderne. Paris: Anthropos.

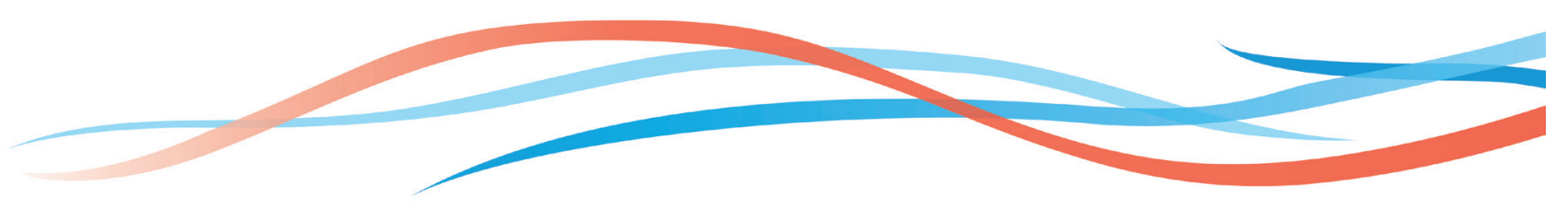

